\title{
MESOSCOPIC SIMULATIONS OF CONCRETE FRACTURE BASED ON X-RAY $\mu C T$ IMAGES OF INTERIAL STRUCTURE
}

\author{
MICHAL NITKA* AND JACEK TEJCHMAN* \\ *Gdansk University of Technology \\ Narutowicza 11/12, 80-233 Gdańsk-Wrzeszcz, Poland \\ e-mail: micnitka@pg.gda.pl, tejchmk@pg.gda.pl
}

Key words: concrete, DEM, fracture, micro-structure, x-ray tomography

\begin{abstract}
In this paper, concrete fracture was experimentally and theoretically investigated at aggregate level. Three-point quasi-static bending tests with notched beams were performed. Microstructure before and after test was observed with the x-ray micro-tomography. In addition, the interfacial transitional zones (ITZs) between aggregate and cement matrix were studied. In order to describe the experimental fracture process, the discrete element method (DEM) was used. Concrete was modelled as random heterogeneous 4-phase material composed of aggregate particles, cement matrix, interfacial transitional zones (ITZs) and air voids. The concrete microstructure was taken directly from microtomography images. The numerical $2 \mathrm{D}$ and 3D outcomes were directly compared with the experimental results. A satisfactory agreement between calculations and experiments was achieved. Attention was paid to the influence of the aggregate shape and ITZs' strength on fracture.
\end{abstract}

\section{INTRODUCTION}

One of the most important and essential phenomena in brittle materials (i.e. concrete) is fracture [1-3]. This process is very complex; it consists main crack with various branches, secondary cracks and micro-cracks). The concrete material has a very complicated heterogeneous structure over many different length scales, changing from the few nanometres (hydrated cement) to the millimetres (aggregate). This micro-structure plays a significant role in the macroscopic behaviour. At the meso-scale, concrete may be considered as a composite material which includes 4 important phases: cement matrix, aggregate, interfacial transition zones (ITZs) and macro-voids $[2,4,5]$. The weakest phase are ITZs which are a porous region of the cement paste around aggregate particles wherein fracture begins [6-9]. The thickness of ITZs is usually about $30-50 \mu \mathrm{m}$. The strongest phase is aggregate whose volume fraction can be as high as $70-75 \%$.

Different methods may be used to describe meso-scale concrete such as continuum models $[4,5,10,11]$ and discrete models [2,12,13]. Within discrete methods, the most common are: a classical particle DEM [14-19], interface element models with constitutive laws based on non-linear fracture mechanics [20,21] and lattice methods [2,13,22-26].

In this paper a classical particle DEM approach is used in order to study the mechanism of the initiation, growth and formation of cracks which affects the macroscopic concrete behaviour [19,27]. The concrete micro-structure was directly taken from real concrete specimens based on 3D images using $\mathrm{x}$-ray micro-tomography and $2 \mathrm{D}$ images from the scanning electron microscope (SEM). The DEM simulations were carried out with the three-dimensional spherical discrete element model YADE which was developed at University of Grenoble [28,29]. The numerical outcomes were directly compared with the experimental results. The advantages and disadvantages of DEM to analyse fracture in concrete were outlined. The effect of ITZs on the concrete strength and crack formation was 
carefully studied. The calculations with round aggregate particles were compared with the outcomes for real-shape aggregate (simulated as the set of clusters of spheres). The 2D and 3D calculations were performed.

\section{EXPERIMENTAL RESULTS}

Concrete used in the three-point bending test included the ordinary Portland cement (CEM I $32.5 \mathrm{R}$ ), gravel, sand and water. The mean aggregate diameter was $d_{50}=2 \mathrm{~mm}$ and the maximum aggregate diameter was $d_{\max }=16$ $\mathrm{mm}$. The specimen included $75 \%$ of aggregate in volume. The beam was $80 \mathrm{~mm}$ high, $320 \mathrm{~mm}$ long and $40 \mathrm{~mm}$ thick. The notch of the height of $8 \mathrm{~mm}$ and width of $3 \mathrm{~mm}$ was located at the mid-span. The measured uniaxial compressive strength $f_{c}$, Young's modulus $E$ and Poisson's ratio $v$ were equal to: $f_{c}=51.81 \mathrm{MPa}, E=36.1$ $\mathrm{GPa}$ and $v=0.22$, respectively. The quasi-static bending test of the concrete beam was performed with a controlled notch opening displacement rate (crack mouth opening displacement (CMOD)) of $0.002 \mathrm{~mm} / \mathrm{min}$ using Instron 5569. A CMOD gauge with the length of $5 \mathrm{~mm}$ was located in the notch at the beam bottom. The test ended for $\mathrm{CMOD}=0.1 \mathrm{~mm}$. The maximum vertical force $F$ was equal to $2.15 \mathrm{kN}$ (the tensile strength was 3.73 $\mathrm{MPa}$ ).After the test, the beam mid-part (height $80 \mathrm{~mm}$, width $50 \mathrm{~mm}$ and depth $40 \mathrm{~mm}$ ) was cut out and placed inside the $x$-ray microtomograph Skyscan 1173. The method allowed to precisely detect cracking of a heterogeneous complex 3D concrete micro-structure and to separate 3 phases (aggregate particles, cement matrix and air voids) (Fig.1). The air void volume was $4.67 \%$. The width of ITZs was determined with the scanning electron microscope Hitachi TM3030 [27]. The width changed between 30-50 $\mu \mathrm{m}$ (Fig.2). The width was not dependent upon the aggregate diameter.

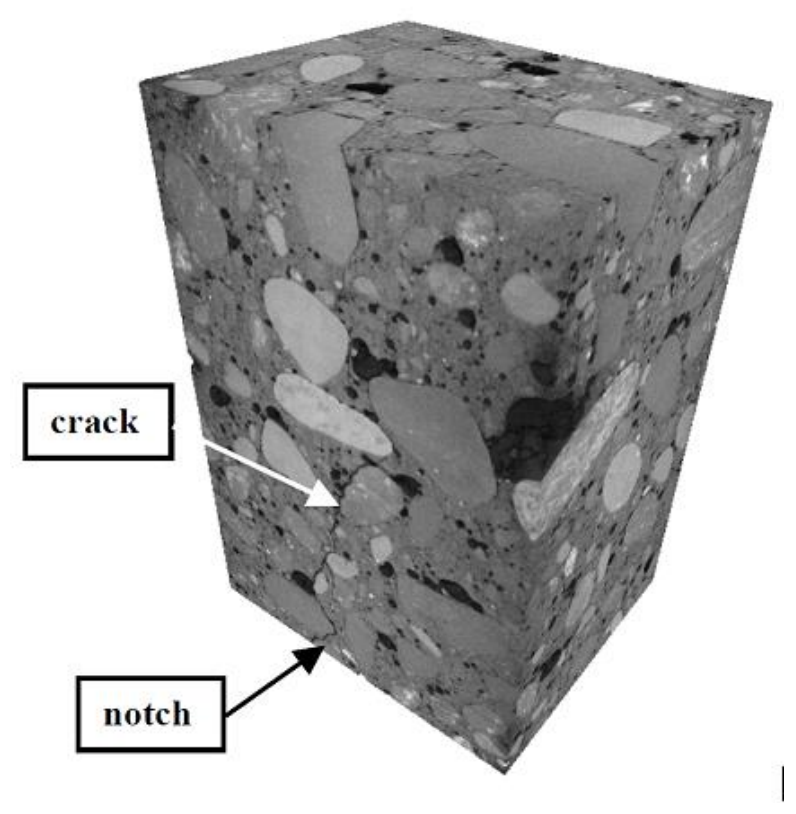

Figure 1: General view of cut-out cracked cuboidal specimen $80 \times 50 \times 40 \mathrm{~mm}^{3}$ obtained by means of $3 \mathrm{D}$ $\mu \mathrm{CT}$

The crack was strongly curved mainly due to presence of aggregate grains (Fig.1). Its shape changed along the specimen depth. The crack propagated in the weakest phase (ITZs) and through the cement matrix. Crack might also propagate through a weak aggregate particle and a macro-void. The macro-crack was created by bridging the interfacial micro-cracks. The crack width in the tensile region changed nonlinearly with the specimen height from $w_{\mathrm{c}}=0.32$ $\mathrm{mm}$ (just above the notch) down to $w_{\mathrm{c}}=0.02 \mathrm{~mm}$ (beam top) (mid-cross-section). The crack width above the notch varied with the specimen depth from $w_{c}=0.32 \mathrm{~mm}$ (at the depth of $5 \mathrm{~mm}$ from the face side) down to $w_{c}=0.13 \mathrm{~mm}$ (at the depth of $35 \mathrm{~mm}$ ). The average crack width and height were: $w_{c}=0.20 \mathrm{~mm}$ and $h_{c}=50 \mathrm{~mm}$, respectively. The crack height changed along the specimen depth, from $h_{c}=45 \mathrm{~mm}$ up to $h_{c}=56 \mathrm{~mm}$ on the front specimen side (Fig.3). 


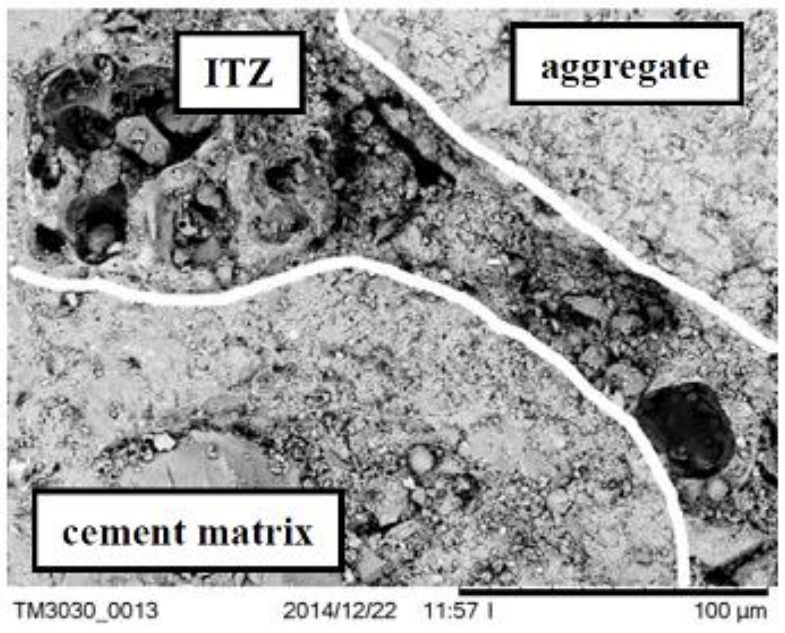

Figure 2: Arbitrary images of ITZs around aggregate in concrete specimen by means of scanning electron microscope (SEM) with magnification factor 1'000

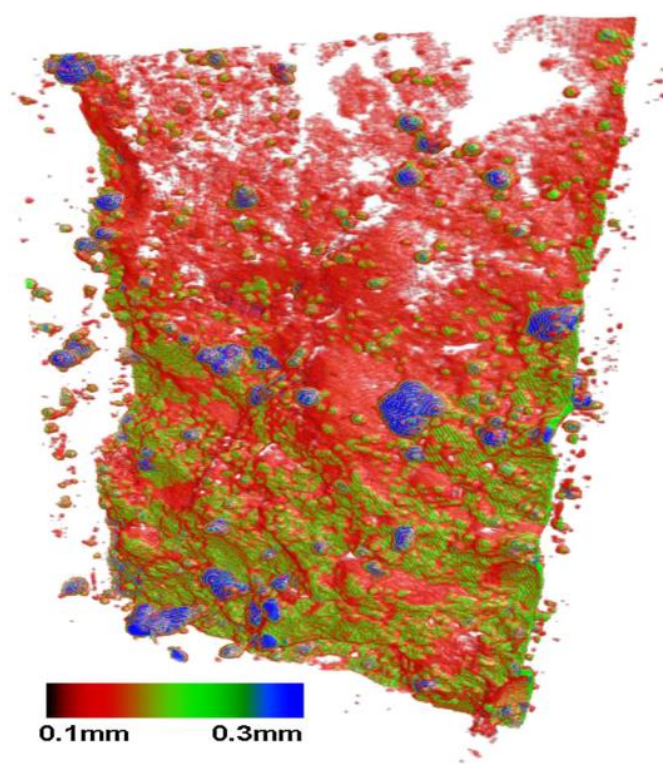

Figure 3: 3D crack visualisation along cuboid depth (colours denote crack width)

The width of the localized zone above the notch on the beam surface, measured by DIC was $w_{l z}=3.11-3.40 \mathrm{~mm}$ [30]. The experimental results were described in detail by Skarzynski and Tejchman [31].

\section{DISCRETE ELEMENT METHOD}

Numerical calculations were performed with the open-source code YADE developed at Grenoble University [28,29]. The local contact deformation is modelled as the particles overlap (so-called soft-particle approach). The interaction force vector between two spherical discrete elements in contact was decomposed into a normal and tangential vector, respectively. The normal forces acting on spheres were modelled by an elastic law with cohesion. The normal and tangential forces were linked to the displacements through the normal stiffness $K_{n}$ and the tangential stiffness $K_{s}$ (Figs.4a and 4b) [28]:

$$
\begin{aligned}
& \vec{F}_{n}=K_{n} U \vec{N} \\
& \vec{F}_{s}=\vec{F}_{s, \text { prev }}+K_{s} \Delta \vec{X}_{s}
\end{aligned}
$$

where $U$ is the overlap between spheres, $\vec{N}$ is the normal vector at the contact point, $\Delta \vec{X}_{S}$ is the increment of the relative tangential displacement and $\vec{F}_{s, \text { prev }}$ is the tangential force from the previous iteration. The stiffnesses were computed as the functions of the modulus of elasticity of the grain contact $E_{c}$ and two neighbouring grain radii $R_{A}$ and $R_{B}$ (to determine the normal stiffness $K_{n}$ ) and the modulus of elasticity $E_{c}$ and Poisson's ratio $v_{c}$ of the grain contact and two neighbouring grain radii $R_{A}$ and $R_{B}$ (to determine the tangential stiffness $K_{S}$ ), respectively [28]:

$$
K_{n}=E_{c} \frac{2 R_{A} R_{B}}{R_{A}+R_{B}}, K_{s}=v_{c} E_{c} \frac{2 R_{A} R_{B}}{R_{A}+R_{B}}
$$

A simple linear elastic contact law was assumed in normal contacts. The contact forces $\vec{F}_{s}$ and $\vec{F}_{n}$ satisfied the cohesive-frictional Mohr-Coulomb equation (Fig.4c)

$$
\left\|\vec{F}_{s}\right\|-F_{\max }^{s}-\left\|\vec{F}_{n}\right\| \tan \mu \leq 0
$$

(before contact breakage)

$$
\left\|\vec{F}_{S}\right\|-\left\|\vec{F}_{n}\right\| \tan \mu \leq 0
$$

(after contact breakage)

where $\mu$ denotes the inter-particle friction angle and $F_{\text {max }}^{s}$ is the cohesive force between spheres. The normal force might be negative down to the minimum value of $F_{\text {min }}^{n}$ (tension) if there was no a geometrical contact between elements. If this minimum normal force between spheres $F_{\text {min }}^{n}$ was reached, the contact was broken. Moreover, if any contacts between grains reappeared, cohesion between them was not taken into account. A crack was considered as open if cohesive forces between grains (Eq.4) 
disappeared when a critical threshold was reached. A choice of a very simple constitutive law (with no numerical reductions) was intended to capture on average various contact possibilities in real concrete. The cohesive force and tensile force were assumed as a function of the cohesive stress $C$ (maximum shear stress at pressure equal to zero), tensile normal stress $T$ and sphere radius $R[28,32]$

$$
F_{\max }^{s}=C R^{2} \text { and } F_{\text {min }}^{n}=T R^{2}
$$

For two elements in contact, the smaller values of $C, T$ and $R$ were used. A local nonviscous damping scheme was applied [33] in order to dissipate excessive kinetic energy in a discrete system.

The following five main local material parameters were needed for our discrete simulations: $E, v, \mu, C$ and $T$ which may be successfully calibrated with real laboratory uniaxial tests on compression and tension of concrete specimens [19]. In addition, the particle radius $R$, particle mass density $\rho$ and damping parameters $\alpha_{d}$ were required. Note that material softening was not assumed in the model. The model was already successfully used for simulating the behaviour of different granular materials [34-36].

In DEM computations, concrete was described as a four-phase material which consist of aggregate, cement matrix, ITZs and air voids. Cement matrix was simulated with round spheres wit diameter from $0.25 \mathrm{~mm}$ up to $2 \mathrm{~mm}$. Air voids correspond to empty spaces. In 2D calculations aggregate was simulated as a cluster composed of small spheres $(0.5 \mathrm{~mm})$ connected to each other as a rigid bodies. Each cluster might include 10-500 spheres. In 3D calculations the round grains (from $2 \mathrm{~mm}$ to 16 $\mathrm{mm}$ ) were solely used to simulate aggregate. Their distribution was random. All aggregate included ITSs. Due to calculation time reduction only middle part of the beam was modelled as the four phase concrete (mesoscale). The remaining beam region (outside the meso-region close to the notch) was simulated with spheres of $d=2-8 \mathrm{~mm}$ (Fig.5).

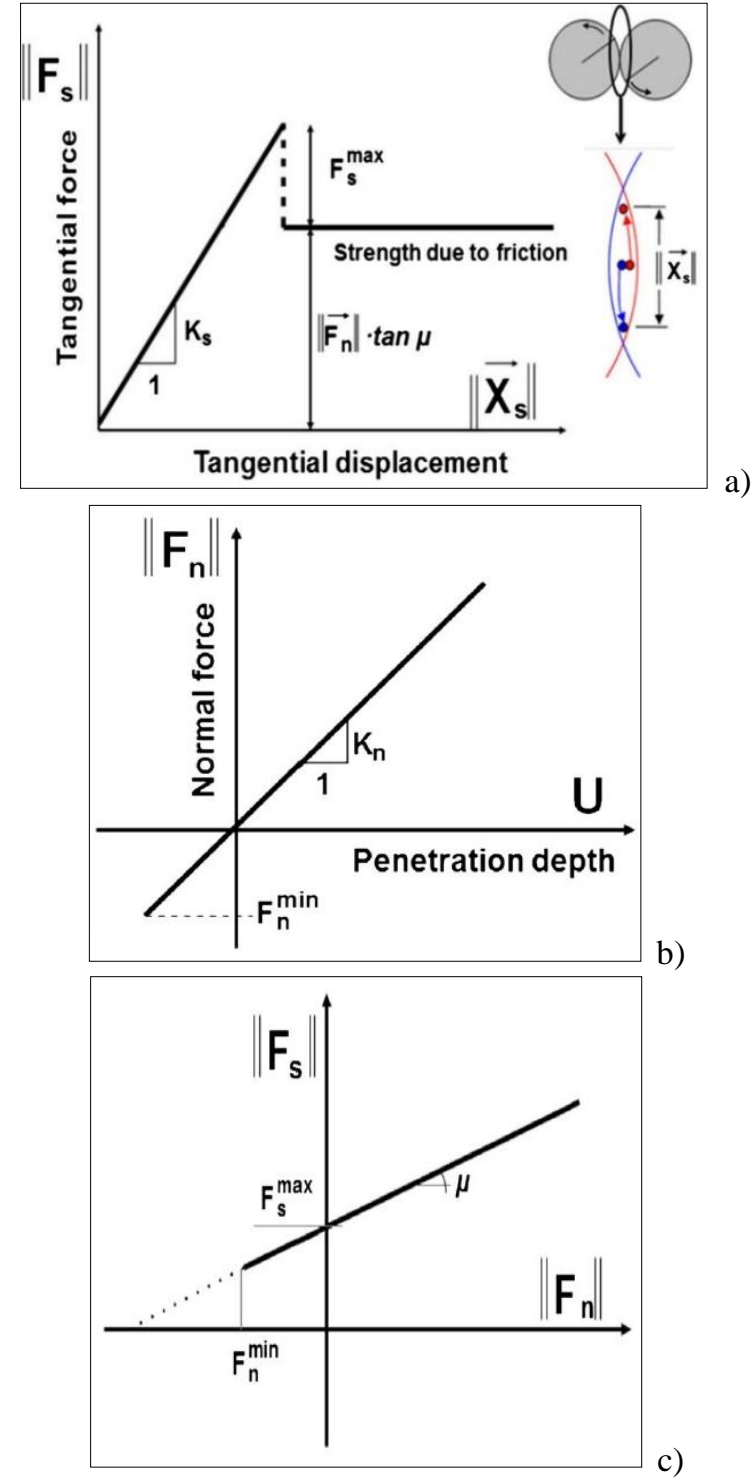

Figure 4: Mechanical response of DEM:

a) tangential contact model, b) normal contact model and c) modified Mohr-Coulomb model [19]

The following parameters of cohesion and tensile strength were used to the particular phase in all calculations: cement matrix $\left(E_{c, c m}=11.2 \quad \mathrm{GPa}, \quad \mathrm{C}_{c m}=140 \quad \mathrm{MPa} \quad\right.$ and $\left.T_{c m}=25 \mathrm{MPa}\right)$ and ITZs $\left(E_{c, I T Z}=7.8 \mathrm{GPa}\right.$, $C_{\text {ITZ }}=100 \mathrm{MPa}$ and $T_{\text {ITZ }}=17.5 \mathrm{MPa}$ ) [27]. The calibration procedure was described by Nitka and Tejchman [19]. In the remaining region outside the meso-region with large grains was described by the constants: $E_{\text {macro }}=12.8 \mathrm{GPa}$, $C_{\text {macro }}=140 \mathrm{MPa}$ and $T_{\text {macro }}=25 \mathrm{MPa}$ [27]. The contact elastic stiffness of the cement matrix and beam macro-zone were directly taken from the laboratory tests. The remaining parameters were constant for all phases and regions: $v_{c}=0.2$ 
(Poisson's ratio of grain contact), $\mu=18^{\circ}$ (interparticle friction angle), $\alpha_{d}=0.08$ (damping parameter) and $\rho=2.6 \mathrm{kG} / \mathrm{m}^{3}$ (mass density). The prescribed damping parameter and velocity did not affect the results [27]. The calculated nominal inertial number $I$ (which quantifies the significance of dynamic effects) was $<10^{-3}$ that always corresponded to a quasi-static regime. The beam in 2D included in total about 25'000 spheres (20'000 elements in the meso-region) and in 3D about 98'000 (96'500 in the meso region). Due to the calculation effort in the $3 \mathrm{D}$ case, the minimum particle in the cement matrix was $0.5 \mathrm{~mm}$ was. The calculation time was equal: 7 days for 2D and 14 days for 3D (using PC with i5 CPU $2.8 \mathrm{GHz}$ ).
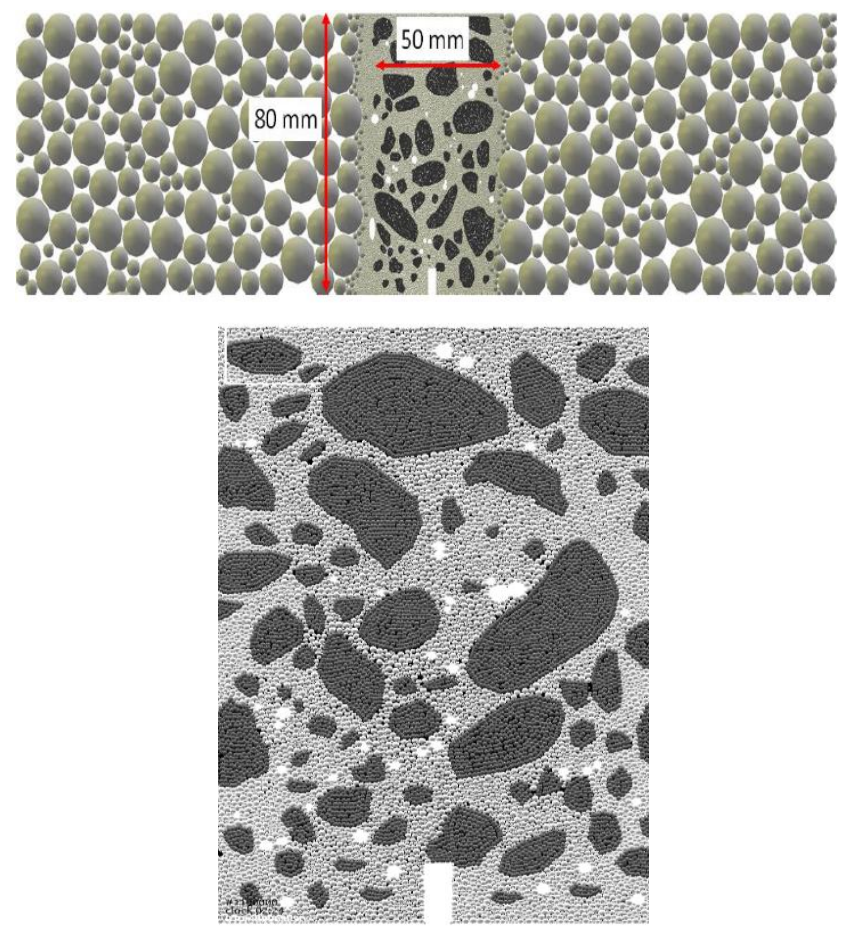

Figure 5: 2D geometry of the entire beam and meso-region (dark grey colour correspond to the aggregate)

\section{NUMERICAL RESULTS}

Figure 6 shows the macroscopic results of the evolution curve (vertical force-CMOD) from DEM as compared to the experimental one. The numerical results show good agreement with the experimental data. For 2D calculations. The maximum calculated vertical force was equal to $F=2.20 \mathrm{kN}$ for
$\mathrm{CMOD}=0.018 \mathrm{~mm}$ (in the experiment: $F=2.18 \mathrm{kN}$ and $\mathrm{CMOD}=0.017 \mathrm{~mm})$. The computed residual force $(\mathrm{CMOD}=0.1 \mathrm{~mm})$ was about $10-20 \%$ higher than in the laboratory test. For the 3D analysis, the computed maximum vertical force was $F_{\max }=2.14 \mathrm{kN}$ for $\mathrm{CMOD}=0.0175 \mathrm{~mm}$ (very close to the experimental outcome). The 3D residual vertical force was also close to the experimental one (about $10 \%$ higher).

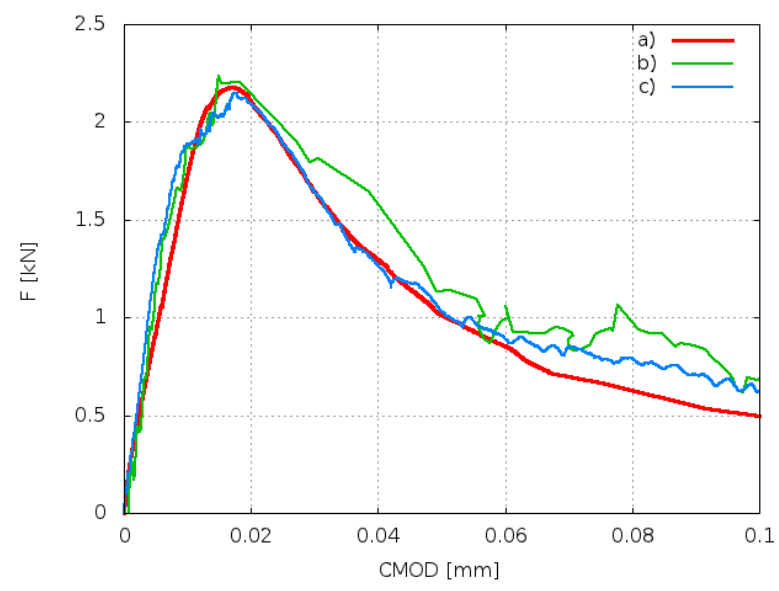

Figure 6: Evolution of vertical force $F$ against displacement CMOD in beam under 3-poin bending:

a) experimental curve, b) 2D DEM analysis $\left(\mathrm{d}_{\min }=0.25 \mathrm{~mm}\right)$ and c) 3D DEM analysis $\left(\mathrm{d}_{\min }=0.5 \mathrm{~mm}\right)$

In Fig.7 the numerical and experimental final crack path was shown in the vertical crosssection at the depth of $10 \mathrm{~mm}$ from the beam face side for $\mathrm{CMOD}=0.1 \mathrm{~mm}$. The calculated crack height after the test was about $h_{c}=50 \mathrm{~mm}$ (75\% of the specimen height) for 2D specimens (Fig. $7 \mathrm{~b})$ and $h_{c}=45 \mathrm{~mm}$ (70\% of the specimen height) for $3 \mathrm{D}$ calculations. The crack length was about $l_{c}=60 \mathrm{~mm}$ for $2 \mathrm{D}$ (similarly as during the experiment), however for 3D calculations the length was lower (about $50 \mathrm{~mm}$ ). The crack width above the notch was about $w_{c}=0.30 \mathrm{~mm}$ for $2 \mathrm{D}$ and $w_{c}=0.36 \mathrm{~mm}$ for $3 \mathrm{D}(\mathrm{CMOD}=0.1$ $\mathrm{mm}$ ), similarly as the experimental values by DIC [30]: $w_{c}=0.28-0.32 \mathrm{~mm}$.

The 3D view of the crack from DEM calculations is shown in Fig.7. With the real aggregate, the calculated crack shape is almost identical as in the experiment (Figs.7a and 7b). The crack was strongly curved due to the presence of aggregate and always propagated through the cement matrix and ITZs, which 
were the weakest phases in the concrete beam. The macro-crack was created above the notch and then moved upwards due to bending. Since ITZs were the weakest phase in concrete, micro-cracking occurred first there. When two interfacial cracks occurred around adjacent aggregates, a crack inside the cement matrix initiated to bridge interfacial cracks so that a connected upward crack path was formed (Fig.8). Note that the macro-crack included always many small branches along its propagation way. For 3D calculations with the spherical aggregate the crack way was straight (Figs.7c and 7d).

The number of broken contacts is demonstrated in Fig.9. The evolution was more irregular and fluctuated for the 2D specimen. The grain contacts started to break at the same moment $(\mathrm{CMOD}=0.005 \mathrm{~mm})$ far before the maximum force was reached $(\mathrm{CMOD}=0.018$ $\mathrm{mm})$. For the 3D specimen the broken contacts reached a higher value. The final normalized amount of broken contacts was higher in 3D calculations $(2.3 \%)$ then in $2 \mathrm{D}$ calculations (1.6\%, Fig.8). The deformed region was significantly larger than the damaged region (Fig.10). For $\mathrm{CMOD}=0.015 \mathrm{~mm}$ (slightly before the maximum vertical force), the contact number with the strength grade above $50 \%$ of the breakage level was 948 (the number of the broken contacts was 60). For the large $\mathrm{CMOD}=0.1 \mathrm{~mm}$ (test end), the contact number with the strength grade above $50 \%$ was 564 and the number of the broken contacts was 600 . The grain contacts were subjected to deformation in the entire crack region (not only at the crack tip).

The map of normal contact forces is presented (Fig.11). The red lines correspond to the high compressive forces (higher than the average ones) and the blue lines to the high tensile forces (lower than the average ones). The remaining forces are marked in green. The thickness of the lines in Fig. 11 represents the magnitude of the normal contact force between two particles.

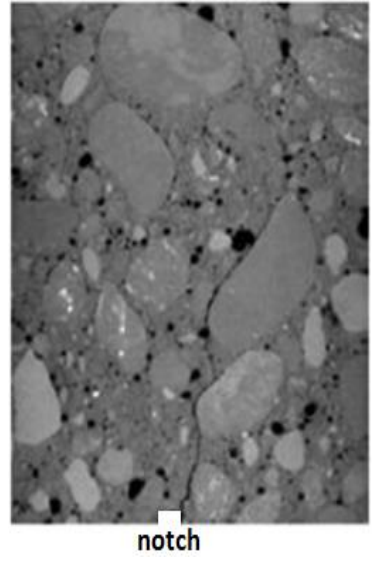

a)
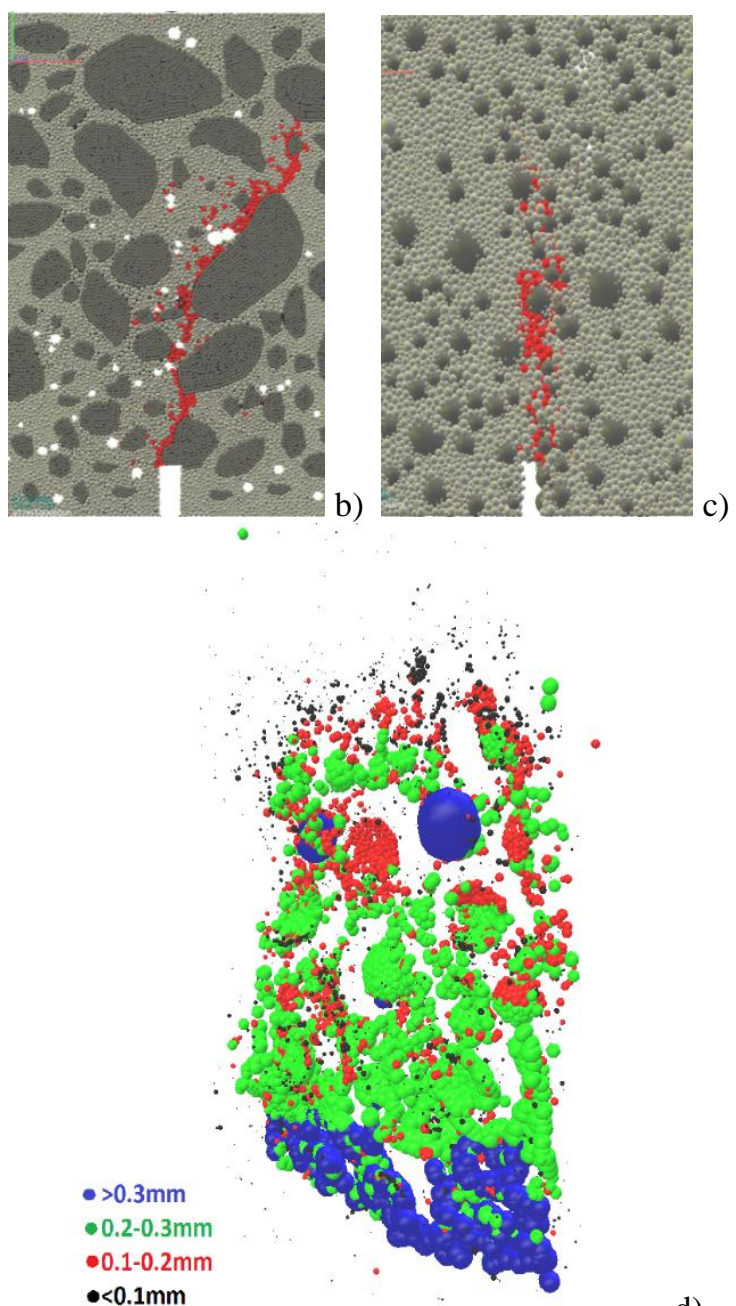

d)

Figure 7: Final crack trajectory in concrete beam above notch after test for CMOD $=0.1 \mathrm{~mm}$ : a) $\mu \mathrm{CT}$ image at depth of $10 \mathrm{~mm}$ from beam face side and $\mathrm{b}$ ) 2D DEM analysis $\left(\mathrm{d}_{\min }=0.25 \mathrm{~mm}\right)$ and c) 3D DEM analysis $\left(\mathrm{d}_{\min }=0.5 \mathrm{~mm}\right)$ (red colour denotes elements with broken contacts, dark grey denotes aggregate, light grey denotes cement matrix and white colour denotes macro-voids) and d) calculated crack region above notch from 3D DEM calculations 


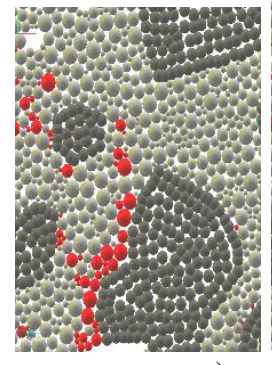

a)

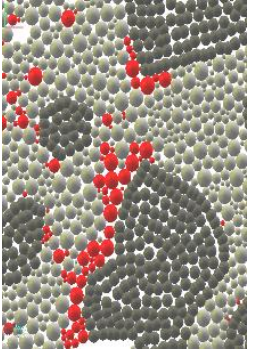

b)

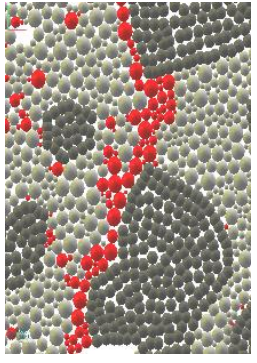

c)
Figure 8: Mechanism of crack formation between aggregate particles from 2D analyses (real aggregate shape modelled by grain clusters) during beam deflection for: a) $\mathrm{CMOD}=0.03 \mathrm{~mm}$,

b) $\mathrm{CMOD}=0.035 \mathrm{~mm}$ and c) $\mathrm{CMOD}=0.040 \mathrm{~mm}$ (dark grey colour - aggregate, light grey colour - cement matrix and red colour - cement matrix spheres with broken contacts)

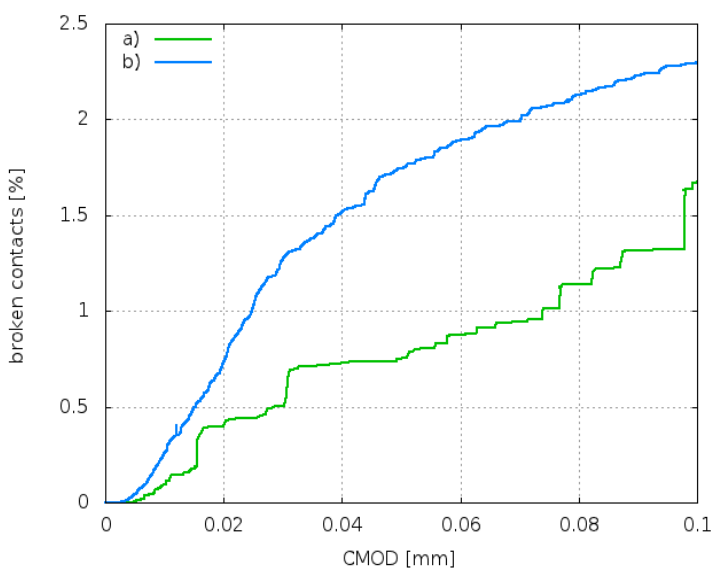

Figure 9: Evolution of broken contact number $n$ in [\%] with respect to total initial contacts number versus CMOD displacement obtained in DEM with: a) 2D model $\left(\mathrm{d}_{\min }=0.25 \mathrm{~mm}\right)$ and $\left.\mathrm{b}\right) 3 \mathrm{D}$ model $\left(\mathrm{d}_{\min }=0.5 \mathrm{~mm}\right)$

The external vertical force was transmitted via a network of contact forces which formed force chains. At the bending onset the contact normal forces were almost uniform in the cement matrix (Fig.11A). The compressive contact forces were obviously in the upper beam region and the tensile ones in the lower beam region. Since when a crack developed (Fig.11B), their distribution due to the grain re-arrangement became strongly non-uniform. The intense tensile area moved up with the propagating crack. The maximum contact forces were about: $20 \mathrm{~N}$ (2D and 3D) (tensile force at the crack tip) and $50 \mathrm{~N}$ (2D) and 40N (3D) (compressive force under the external vertical force $F$ ). Some pronounced compressive forces also existed close to the crack due to strong shear along its non-regular rough surface that caused the so-called interlocking action [37]. The maximum shear force (connected to the maximum normal force) was close to the crack $(20 \mathrm{~N})$.

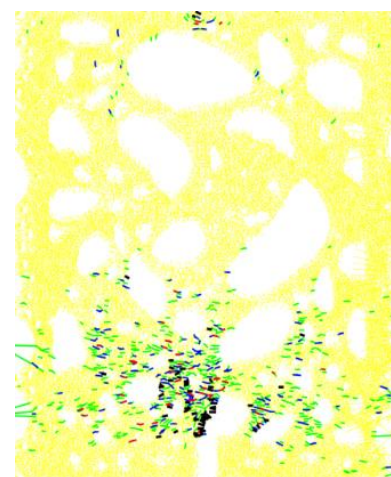

a)

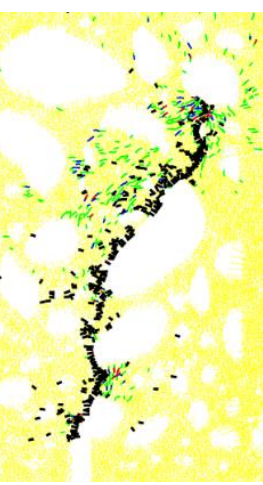

b)
Figure 10: Contact distribution with their strength from 2D DEM for CMOD=0.015 $\mathrm{mm}$ (a) and

$\mathrm{CMOD}=0.1 \mathrm{~mm}$ (b) with real non-regularly-shaped aggregate (yellow colour - all contacts, black colour broken contacts, green colour - contacts with strength grade above $50 \%$, blue colour - contacts with strength grade above $70 \%$ and red colour - contacts with strength grade above $90 \%$ )

Finally the effect of ITZs was studied in 2D calculations. The final crack pattern was compared to the one obtained from the laboratory test (Fig.7a). The cohesion (Fig.12) and stiffness of the particle contact (Fig13) were changed. If there were no ITZs, the crack was more straight (Figs.12a and 13a). If ITZs were weaker about $30 \%$ than the cement matrix, the calculated curved crack was similar as the experimental one (Figs.12b and 13b). If they were weaker by $50 \%$, the crack was more dispersed (Fig.12c) and more concentrated around aggregate particles (Fig.13c).

\section{CONCLUSIONS}

The following conclusions may be derived based on our DEM calculation outcomes:

The aggregate shape extremely strongly affected the shape and length of the discrete macro-crack. The crack was shorter in length and more straight with round aggregate. The width of the macro-crack was similar. The beam strength was more realistically captured with the smaller minimum particles diameter in 
2D analyses $\left(d_{\min }=0.25 \mathrm{~mm}\right)$ and in 3D simulations $\left(d_{\min }=0.5 \mathrm{~mm}\right)$. The circular aggregate shape contributed to the beam strength (by 20\%).

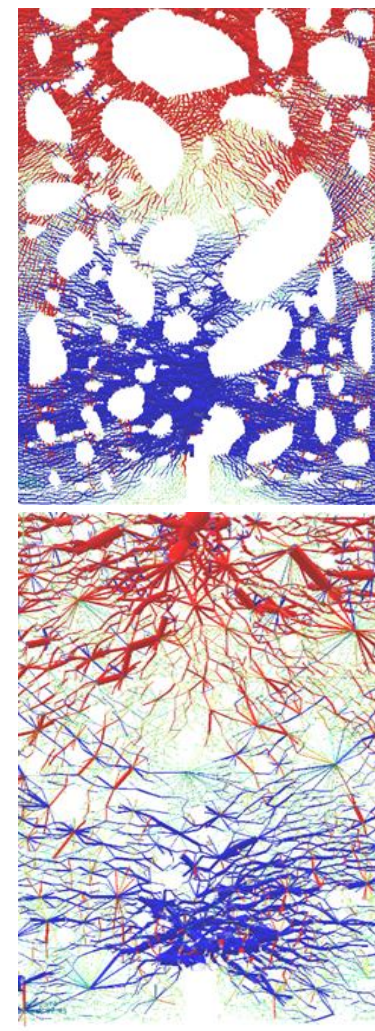

A)

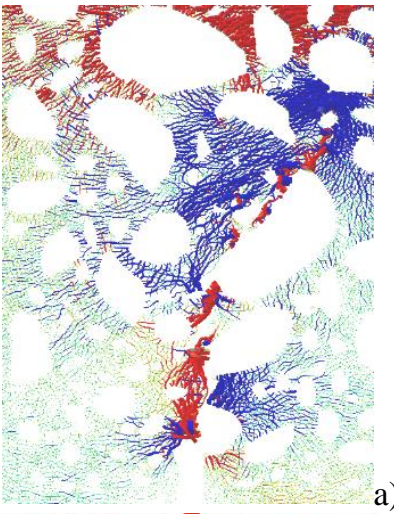

a)

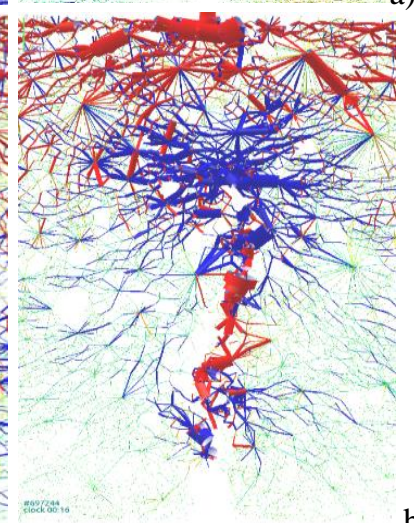

B)

Figure 11: Maps of contact normal forces between grains obtained from: a) $2 \mathrm{D}$ model $\left(d_{\min }=0.25 \mathrm{~mm}\right)$ and b) $3 \mathrm{D}$ model $\left(d_{\min }=0.5 \mathrm{~mm}\right)$ for A) $\mathrm{CMOD}=0.015 \mathrm{~mm}$ and $\mathrm{B}$ ) $\mathrm{CMOD}=0.1 \mathrm{~mm}$ (red colour denote compression and blue colour denote tension)

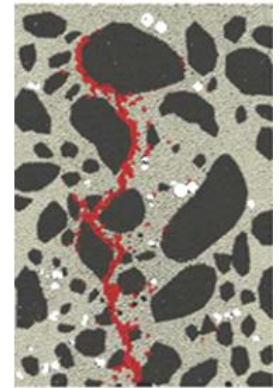

a)

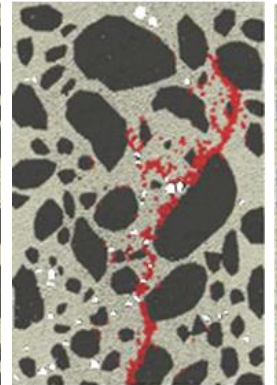

b)

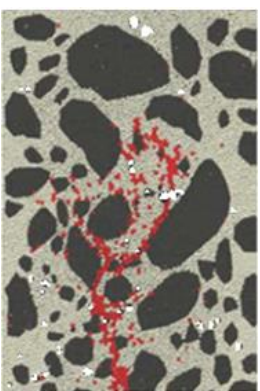

c)
Fig.12: Effect of different constant $E_{I T Z}$ on fracture for $\mathrm{CMOD}=0.10 \mathrm{~mm}$ in DEM analyses: a) $E_{n, I T Z}=11.2 \mathrm{GPa}$, b) $E_{c, I T Z}=7.8 \mathrm{GPa}$, c) $E_{c, I T Z}=5.6 \mathrm{GPa}$ (with $T_{\text {ITZ }}=14 \mathrm{MPa}$ )

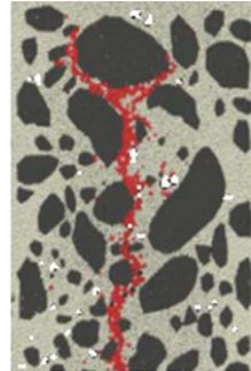

a)

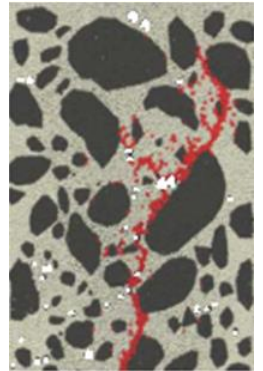

b)

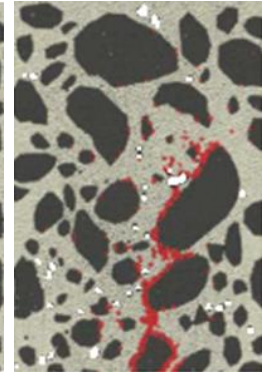

c)
Fig.13: Effect of different constant $T_{I T Z}$ on fracture for $\mathrm{CMOD}=0.10 \mathrm{~mm}$ in DEM calculations:

a) $T_{I T Z}=20 \mathrm{MPa}$, b) $T_{I T Z}=14 \mathrm{MPa}$ and c) $T_{I T Z}=10 \mathrm{MPa}$ (with $E_{I T Z}=7.8 \mathrm{GPa}$ )

The macro-crack was always curved due to a stochastic distribution of aggregate with ITZs. It had a varying width. It was created by bridging the interfacial micro-cracks. It possessed many small branches. The single micro-cracks also occurred far beyond the macro-crack. The external vertical force was transmitted via a network of contact forces which formed force chains of a different intensity. The compressive normal contact forces (connected to the tangential contact forces) developed also along the macro-crack due to aggregate inter-locking.

The evolution of broken contacts was more non-uniform for non-circular aggregate and in 3D calculations. The breakage rate was similar for each aggregate shape up to $\mathrm{CMOD}=0.015 \mathrm{~mm}$. At the peak strength $(\mathrm{CMOD}=0.018 \mathrm{~mm})$, the number of broken contact was higher for non-circular aggregate due to stress concentrations at sharp edges. Later its number became larger with circular grains (even by 50\%). The final number of broken contacts was similar independently of the aggregate shape. The relative number of all broken contacts was by $50 \%$ higher both in 3D simulations than in 2D simulations $(2.3 \%$ versus $1.5 \%$ ) and with $d_{\min }=0.25 \mathrm{~mm}$ than with $d_{\min }=0.25 \mathrm{~mm}$ in $2 \mathrm{D}$ simulations $(2.5 \%$ versus $1.5 \%)$. The initial breakage rate was also significantly higher in 3D simulations.

\section{ACKNOWLEDGEMENT}

Research work has been carried out by the authors as a part of the project "Experimental and numerical analysis of coupled 
deterministic-statistical size effect in brittle materials" financed by the National Research Centre NCN (UMO-2013/09/B/ST8/03598).

\section{REFERENCES}

[1] Bažant, Z. and Planas, J. 1997. Fracture and size effect in concrete and other quasibrittle materials. CRC Press LLC, Boca Raton.

[2] Lilliu, G. and van Mier, J.G.M. 2003. 3D lattice type fracture model for concrete. Engineering Fracture Mechanics 70, $927-$ 941.

[3] Tejchman J. and Bobiński J. 2013. Continuous and discontinuous modelling of fracture in concrete using FEM. Springer, Berlin-Heidelberg (eds. W. Wu and R. I. Borja).

[4] Gitman, I. M., Askes, H. and Sluys, L.J. 2008. Coupled-volume multi-scale modelling of quasi-brittle material. European Journal of Mechanics A/Solids 27, 302-327.

[5] Skarżyński, Ł. and Tejchman, J. 2010. Calculations of fracture process zones on meso-scale in notched concrete beams subjected to three-point bending. European Journal of Mechanics A/Solids 29 (4), 746760.

[6] Baseman, L. E. and McCuen, R. H. 2011. Estimating the distribution of air voids in concrete. Civil Engineering Dimension 13(1), 15-20.

[7] Scrivener, K.L., Crumbie, A.K. and Laugesen, P. 2004. The interfacial transition zone (ITZ) between cement paste and aggregate in concrete. Interface Science 12, 411-421, Springer Netherlands.

[8] Mondal, P., Shah, S. P. and Marks, L.D. 2009. Nanomechanical properties of interfacial transition zone in concrete. Nanotechnology in Construction 3, Springer, 315-320.

[9] Königsberger, M., Pichler, B. and Hellmich, Ch. 2014. Micromechanics of ITZ-aggregate interaction in concrete Part II: strength upscaling. Journal of American
Ceramic Society. Journal of American Ceramic Society 97, 543-551.

[10]Kim, S.M. and Abu Al-Rub, R. K. 2011. Meso-scale computational modeling of the plastic-damage response of cementitious composites. Cement and Concrete Research 41, 339-358.

[11] Shahbeyk, S., Hosseini, M. and Yaghoobi, M. 2011. Mesoscale finite element prediction of concrete failure. Computational Materials Science 50 (7), 1973-1990.

[12] Hentz, S., Daudeville, L. and Donze, F. 2004. Identification and validation of a Discrete Element Model for concrete. Journal of Engineering Mechanics ASCE 130 (6), 709-719.

[13]Kozicki, J. and Tejchman, J. 2008. Modelling of fracture processes in concrete using a novel lattice model. Granular Matter 10, 377-388.

[14]Donze, F.V., Magnier, S.A., Daudeville, L. and Mariotti, C. 1999. Numerical study of compressive behaviour of concrete at high strain rates. Journal for Engineering Mechanics, 122(80), 1154-1163.

[15]D'Addetta, G.A., Kun, F. and Ramm, E. 2002. On the application of a discrete model to the fracture process of cohesive granular materials. Granular Matter 4, 7790.

[16]Potyondy, D.O. and Cundall, P. A. 2004. A bonded-particle model for rock. Int. J. Rock Mechanics and Mining Sciences. 41(8), 1329-1364.

[17]Dupray, F., Malecot, Y., Daudeville, L. and Buzaud, E. 2009. A mesoscopic model for the behaviour of concrete under high confinement. International Journal for Numerical and Analytical Methods in Geomechanics 33, 1407-1423.

[18] Obermayr, M., Dressler, K., Vrettos, C. and Eberhard, P. 2013. A bonded-particle model for cemented sand. Computers and Geotechnics 49, 299-313.

[19]Nitka, M. and J. Tejchman, J. 2015. Modelling of concrete behaviour in uniaxial compression and tension with DEM. Granular Matter 17, 1, 145-164. 
[20] Carol, I., López, C.M. and Roa, O. 2001. Micromechanical analysis of quasi-brittle materials using fracture-based interface elements. Int $J$ Numerical Methods in Engineering 52,193-215.

[21] Caballero, A., Carol, I. and López C.M. 2006. New results in 3D meso-mechanical analysis of concrete specimens using interface elements, Computational Modelling of Concrete Structures, EURO$C$ (eds.:G. Meschke, R. de Borst, H. Mang and N. Bićanić), Taylor and Francis Group, 43, 52.

[22] Herrmann, H. J., Hansen, A. and Roux, S. 1989. Fracture of disordered, elastic lattices in two dimensions. Physical Rev. B, 39, 637-647.

[23] Jirásek, M. and Bažant Z. P. 1995. Particle model for quasi-brittle fracture and application to sea ice. J. Eng. Mech. 121(9), 1016-1025.

[24] Schlangen, E. and Garboczi, E. J. 1997. Fracture simulations of concrete using lattice models: computational aspects. Engineering Fracture Mechanics 57, 319332.

[25]Cusatis, G., Bažant, Z.P. and Cedolin, L. 2003. Confinement-shear lattice model for concrete damage in tension and compression: I. theory. ASCE Journal of Engineering Mechanics 129, 12, 14391448.

[26]Bolander, J.E. and Sukumar, N. 2005. Irregular lattice model for quasi-static crack propagation. Phys Rev B 71, 094106.

[27] Skarżyński, Ł., Nitka, M., and Tejchman, J. 2015 Modelling of concrete fracture at aggregate level using FEM and DEM based on x-ray $\mu \mathrm{CT}$ images of internal structure. Engineering Fracture Mechanics 10, 147:13-35

[28] Kozicki, J. and Donze, F. 2008. A new open-source software developer for numerical simulations using discrete modeling methods. Computer Methods in Applied Mechanics and Engineering 197:4429-4443.

[29] Šmilauer, V. and Chareyre, B. 2011. Yade DEM Formulation. Manual.
[30] Skarżyński, L. and Tejchman, J. 2013. Experimental investigations of fracture process in plain and reinforced concrete beams under bending. Strain 49:521-543.

[31] Skarżyński, Ł., Tejchman, J. 2016. Experimental investigations of fracture process in concrete by means of x-ray micro-computed tomography. Strain:121168. doi: 10.1111

[32] Ergenzinger, Ch., Seifried, R. and Eberhard, P. 2011. A discrete element model to describe failure of strong rock in uniaxial compression. Granular Matter 13, 341-364.

[33]Cundall, P. A. and Hart, R. 1992. Numerical modelling of discontinua. Engineering Computations 9:101-113.

[34]Widulinski, L., Tejchman, J., Kozicki, J. and Leśniewska, D. 2011. Discrete simulations of shear zone patterning in sand in earth pressure problems of a retaining wall. Int. J. Solids and Structures 48, 7-8, 1191-1209.

[35]Kozicki, J., Niedostatkiewicz, M., Tejchman, J. and Mühlhaus, H.-B. 2013. Discrete modelling results of a direct shear test for granular materials versus $\mathrm{FE}$ results. Granular Matter 15, 5, 607-627.

[36]Kozicki, J., Tejchman, J. and Mühlhaus, H.-B. 2014. Discrete simulations of a triaxial compression test for sand by DEM. Int. J. Num. Anal. Methods Geom. 38, 1923-1952.

[37]Eliáŝ, J. and Stang, H. 2012. Lattice modeling of aggregate interlocking in concrete. Int. J. Fracture 175: 1-11. 